\title{
Infecção sistêmica por Yersinia enterocolitica em chinchilas (Chinchilla laniger) ${ }^{1}$
}

\author{
Luciana Sonne ${ }^{2}$, Djeison L. Raymundo ${ }^{3}$, Fabiana M. Boabaid ${ }^{3}$, Mauro R. Borba ${ }^{4}$, \\ Gustavo G.M. Snel ${ }^{5}$, Marcos J.P. Gomes ${ }^{5}$ e David Driemeier ${ }^{3 *}$
}

\begin{abstract}
Sonne L., Raymundo D.L., Boabaid F.M., Borba M.R., Snel G.G.M., Gomes M.J.P. \& Driemeier D. 2012. [Systemic infection by Yersinia enterocolitica in chinchillas (Chinchilla laniger).] Infecção sistêmica por Yersinia enterocolitica em chinchilas (Chinchilla laniger). Pesquisa Veterinária Brasileira 32(5):379-382. Setor de Patologia Veterinária, Faculdade de Veterinária, Universidade Federal do Rio Grande do Sul, Av. Bento Gonçalves 9090, Porto Alegre, RS 91540-000, Brazil. E-mail: davetpat@ufrgs.br

Yersinia enterocolitica is a Gram-negative bacterium, which causes infections in several mammalian species. It is often recognized as an agent causing intestinal and mesenteric lymph nodes lesions. However, Yersinia enterocolitica infection may also become systemic, with lesions in others organs such as liver and spleen. This paper describes outbreaks of systemic infection due to Yersinia enterocolitica in two commercial chinchilla breeders in Rio Grande do Sul (Brazil). Owners reported that affected animals showed apathy, anorexia prior to death. Macroscopic examination performed in 13 animals revealed splenomegaly, hepatomegaly and multifocal whitish pinpoint foci in liver, spleen, lung, kidney and intestine. Microscopically, the affected tissues had infiltration of neutrophils and macrophages, as well as fibrin and necrosis with central areas containing cocobacilli bacteria. Yersinia enterocolitica was isolated from liver, spleen, lung and intestine samples from animals of both breeders, and from feces of chinchillas of one of the breeders. Therefore, yersiniosis is a disease to be investigated in cases of mortality of chinchillas.
\end{abstract}

INDEX TERMS: Chinchilla laniger, infections, Yersinia enterocolitica.

RESUMO.- Yersinia enterocolitica é uma bactéria Gramnegativa que causa infecções em diversas espécies de mamíferos. 0 agente, geralmente, provoca infecções restritas ao intestino e linfonodos mesentéricos, porém a infecção pode se tornar sistêmica ocasionando lesões em outros órgãos como fígado e baço. Neste trabalho descrevem-se dois surtos de infecções sistêmicas causadas pela Yersinia enterocolitica em criatórios comerciais de chinchilas no Rio Grande do Sul (Brasil). Os proprietários relatavam que os

\footnotetext{
${ }^{1}$ Recebido em 18 de outubro de 2011.

Aceito em 12 de dezembro de 2011.

${ }^{2}$ Laboratório de Patologia Veterinária, Faculdade de Agronomia e Medicina Veterinária, Universidade de Brasília (UnB), Campus Darcy Ribeiro, Via L4 s/n, Brasília, DF 70910-900, Brasil.

${ }^{3}$ Setor de Patologia Veterinária, Faculdade de Veterinária, Universidade Federal do Rio Grande do Sul (UFRGS), Avenida Bento Gonçalves 9090, Bairro Agronomia, Porto Alegre, RS 91540-000, Brasil. *Autor para correspondência: davetpat@ufrgs.br

${ }^{4}$ Setor de Epidemiologia Veterinária, Faculdade de Medicina Veterinária e Zootecnia, Universidade de São Paulo (USP), Cidade Universitária, Av. Prof. Dr. Orlando Marques de Paiva 87, São Paulo, SP 05508-270, Brasil.

${ }^{5}$ Laboratório de Bacteriologia Veterinária, UFRGS, Porto Alegre, RS.
}

animais acometidos apresentavam apatia, anorexia e morte. Foram encaminhados 13 animais para a realização de necropsia. No exame post mortem dos animais observou-se esplenomegalia, hepatomegalia e áreas multifocais esbranquiçadas no fígado, baço, pulmões, rins e intestino. No exame microscópico visualizou-se infiltrado inflamatório de neutrófilos e macrófagos, necrose, deposição de fibrina e ocasionalmente pode ser observado coco-bacilos no centro das áreas de necrose. No cultivo bacteriológico obteve-se o crescimento de Yersinia enterocolitica nos animais provenientes dos dois criatórios. 0 agente foi isolado de amostras no fígado, baço, intestino e pulmões dos animais necropsiados, além do cultivo de fezes de animais de uma das propriedades acometidas. A yersiniose, portanto, é uma patologia que deve ser investigada em casos de mortalidade de chinchilas.

TERMOS DE INDEXAÇ̃̃O: Chinchilla laniger, infecção, Yersinia enterocolitica.

\section{INTRODUÇÃO}

Yersinia enterocolitica é um coco bacilo Gram-negativo, que pode causar infecções em diversas espécies como 
bovinos, ovinos, suínos, cervídeos, equinos, caninos, lagomorfos e roedores (Pai et al. 1980, Fukushima et al. 1983, 1984, Slee \& Skilbeck 1992, Donnelly 2004, Fenwick \& Collet 2004). É um patógeno facultativo intracelular que tem sua multiplicação no sistema fagocítico mononuclear do hospedeiro (Fenwick \& Collet 2004). A infecção ocorre por via oral através da ingestão de comida ou água contaminada (Bottone 1999). O agente causa uma doença entérica levando a danos no epitélio do íleo, ceco e cólon resultando em lesões hemorrágicas e ulcerativas na mucosa intestinal dos animais acometidos. Também pode ser observada hiperplasia linfoide em placas de Peyer e linfonodos mesentéricos (Donnelly 2004). Em camundongos, a Yersinia enterocolitica replica-se no intestino delgado com posterior invasão dos folículos linfoides das placas de Peyer, podendo disseminar-se para outros órgãos como fígado e baço. Nesses órgãos e tecidos a Yersinia sp. replica-se predominantemente extracelular e forma microcolônias (Oellerich et al. 2007). A disseminação do agente pode ocorrer por via linfática ou sanguínea (Autenrieth \& Firsching 1996). A infecção sistêmica em chinchilas resulta em múltiplos microabscessos no fígado, baço e pulmões, ocasionando a morte do animal (Donnelly 2004). Inicialmente os microabscessos formados por Yersinia enterocolitica no fígado e baço são constituídos primariamente por neutrófilos e em estágios posteriores infiltração de células mononucleares (Oellerich et al. 2007). 0 agente já foi isolado de amostras de fezes, fígado, baço e no sangue de chinchilas infectadas experimentalmente (Raevuori et al. 1979). 0 presente trabalho descreve dois surtos de infecção sistêmica por $Y$. enterocolitica em propriedades comerciais de chinchilas (Chinchilla laniger) no estado do Rio Grande do Sul.

\section{MATERIAL E MÉTODOS}

Foram encaminhadas 13 chinchilas (Chinchilla laniger) para o exame de necropsia no Setor de Patologia Veterinária (SPV), Universidade Federal do Rio Grande do Sul (UFRGS). Os animais eram provenientes de 2 criatórios comerciais do Rio Grande do Sul (Brasil), 7 chinchilas de uma propriedade localizada no município de Cambará do Sul e 6 do município de Maquiné. Os dados epidemiológicos, sinais clínicos e as informações sobre o manejo produtivo das chinchilas foram obtidos junto aos proprietários e durante a visita da equipe do SPV-UFRGS ao estabelecimento de Cambará do Sul.

Realizou-se o exame macroscópico dos animais sendo após realizada a coleta dos órgãos em solução de formol 10\%. Os órgãos foram processados por técnicas rotineiras de histologia e corados pela hematoxilina e eosina (HE) e pela coloração de Brown-Hoops (Prophet et al. 1992).

Fragmentos de fígado, baço, intestino e pulmões de 8 animais com alterações macroscópicas e amostras de fezes de 4 animais, que apresentavam sinais clínicos, do criatório de Cambará do Sul foram coletados e encaminhados para o Laboratório de Bacteriologia Veterinária (LABACVET) da UFRGS. Amostras de fígado, baço, pulmão e intestino foram retirados com o auxílio de alça bacteriológica ao rubro e homogeneizadas em $3 \mathrm{ml}$ de solução fisiológica estéril. As amostras de fezes no interior dos intestinos foram homogeneizadas em água peptonada tamponada na razão de 1:10. Para cada amostra, alíquotas do homogeneizado $(10 \mu \mathrm{l})$ foram semeadas em duplicata em ágar sangue e ágar MacConkey; incubadas em aerobiose a $37^{\circ} \mathrm{C}$ e a $25^{\circ} \mathrm{C}$ por $24-48$ horas. Paralelamente, as alíquotas dos homogeneizados foram inoculadas em caldo seletivo GN Hajna; incubadas a $4^{\circ} \mathrm{C}$ e plaqueadas semanalmente em ágar MacConkey por até 3 semanas, segundo as recomendações sugeridas por Quinn et al. (1999). As colônias suspeitas foram repicadas e identificadas bioquimicamente por um sistema miniaturizado comercial (API 20E, Biomerieux) e testes complementares. Os testes de sensibilidade aos antimicrobianos das amostras identificadas foram realizados em meio sólido, através do método de difusão em disco, conforme as normativas do NCCLS (2002).

\section{RESULTADOS}

O criatório comercial de Cambará do Sul possuía um plantel de 1600 animais e o criatório de Maquiné de aproximadamente 500 chinchilas. Os proprietários relatavam que os animais apresentavam apatia, anorexia e morte. Observou-se uma taxa de mortalidade de $15,8 \%$ dos animais da criação de Cambará do Sul no período do surto; no outro criatório não foi possível determinar a taxa de mortalidade pela falta de dados do número total de óbitos no criatório. Os criatórios utilizavam uma taxa de fêmeas para macho de 6:1,10:1,12:1 ou 18:1 dependendo da capacidade reprodutiva do macho. Os casos de mortalidade ocorriam em todas as faixas etárias. As fêmeas eram os animais mais acometidos, porém o número total de fêmeas nos criatórios era em média 10 vezes o número de machos. Os animais recebiam ração comercial peletizada e água através de bebedouros. Nas gaiolas era colocado maravalha e uma área com pó de mármore para a higienização dos mesmos.

Das treze chinchilas analisadas, 11 eram fêmeas e 2 machos. No exame macroscópico observou-se esplenomegalia $(5 / 13)$ e hepatomegalia $(7 / 13)$. Foram observadas múltiplas pequenas áreas esbranquiçadas que por vezes se confluíam e formavam extensas áreas no parênquima hepático (7/13) (Fig.1A). Áreas esbranquiçadas múltiplas, por vezes formando nódulos, também foram visualizadas no baço (5/13) (Fig.1B), intestino (3/13) (Fig.1C), pulmões (1/13) e rins $(1 / 13)$ dos animais analisados.

0 exame microscópico do fígado, baço, intestino, pulmão e rim revelou microabscessos multifocais constituído de infiltrado de neutrófilos e macrófagos (Fig.1D), com áreas de necrose e deposição de fibrina. Ocasionalmente foram visualizados coco bacilos no centro das áreas necróticas. Essas lesões histológicas foram observadas no fígado de 9 chinchilas, no baço de 5 animais e no pulmão e rim de 1 animal. Em 2 animais não foram observadas lesões macroscópicas hepáticas significativas, porém o exame histológico demonstrou a presença de microabscessos no fígado. $O$ intestino de 3 chinchilas apresentava enterite necrótica com bactérias na mucosa intestinal; em um dos animais visualizou-se infiltrado de histiócitos moderado nas placas de Peyer. As bactérias, quando estavam presentes, foram coradas em vermelho pela coloração de Brown-Hoops revelando com isso serem bactérias Gram-negativas.

No cultivo bacteriano dos tecidos das 8 chinchilas observou-se o crescimento de Yersinia enterocolitica, obtendo-se o crescimento principalmente no fígado $(6 / 8)$, seguido pelo baço (2/8), intestino (2/8) e pulmão $(2 / 8)$. 0 cultivo bacteriano das fezes de 4 chinchilas, coletadas 


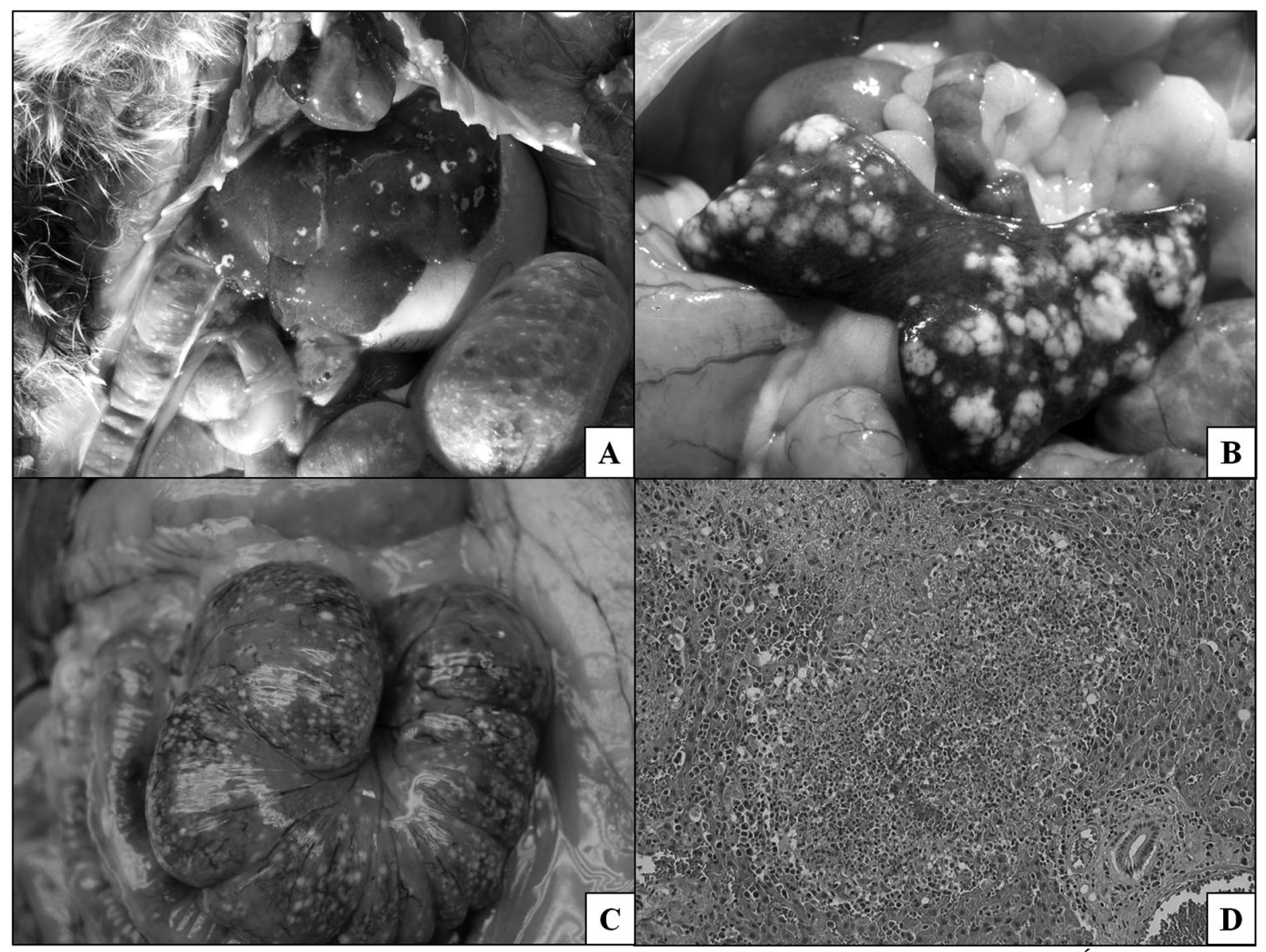

Fig.1. Lesões macroscópicas e microscópicas de infecção por Yersinia enterocolitica em chinchila. (A) Áreas esbranquiçadas no parênquima hepático. (B) Esplenomegalia e áreas esbranquiçadas no baço. (C) Múltiplos nódulos esbranquiçados no intestino. (D) Fígado com infiltrado inflamatório misto, restos necróticos e bactérias (Yersinia enterocolitica) no centro da lesão. HE, obj.20x.

no criatório de Cambará do Sul, revelou o isolamento de Yersinia enterocolitica em 3 desses animais (duas fêmeas e um macho). Esses animais apresentavam apatia e anorexia, porém as fezes se apresentavam de consistência e coloração normal. 0 teste de sensibilidade aos antimicrobianos revelou sensibilidade à enrofloxacina, sulfazotina, tetraciclina, lincomicina, cefalexina, vancomicina, florfenicol, norfloxacina e amicacina; e resistência a ampicilina e tiamulina. Com base nesses resultados optou-se pela utilização de enrofloxacina $10 \mathrm{mg} / \mathrm{kg}$ por via oral duas vezes ao dia durante 10 dias em todo o plantel, visto que muitos animais tinham contato direto e conviviam no mesmo ambiente com os animais acometidos. Medidas de higiene das gaiolas também foram adotadas como a limpeza frequente (2-3 vezes por semana) com troca de maravalha e pó de mármore, e a desinfecção das gaiolas com hipoclorito de sódio. Após o tratamento antimicrobiano e com a adoção dessas medidas houve uma redução significativa no número de mortes do plantel dos dois criatórios comerciais.

\section{DISCUSSÃO E CONCLUSÃO}

Yersinia enterocolitica causa uma infecção entérica, muitas vezes limitada aos linfonodos mesentéricos, mas pode generalizar-se em alguns casos ocasionando lesões viscerais (Oellerich et al. 2007). Lesões macroscópicas como esplenomegalia, hepatomegalia e múltiplos nódulos esbranquiçados no fígado, baço, intestino, rins e pulmões foram observados nas chinchilas desses surtos. Raevuori et al. (1979) descreveu lesões ulcerativas no íleo, esplenomegalia e hepatomegalia com isolamento de $Y$. enterocolitica no fígado, baço e sangue de chinchilas que morreram devido à infecção experimental. Meningoencefalite purulenta, pneumonia catarral, linfadenite e artrite foram observados em infecções experimentais pela bactéria em coelhos (Vesselinova et al. 2001). No exame microscópico das chinchilas foram visualizadas bactérias no centro de áreas necrosadas com infiltrado inflamatório de neutrófilos e macrófagos localizados principalmente no fígado e baço. A enterite necrótica também foi um achado microscópico de grande importância, porém nesse caso somente em 3 chinchilas foram observadas lesões intestinais. A ausência dessas lesões intestinais em alguns animais pode ser explicada já que muitos desses apresentavam alterações post mortem significativas dificultando assim a análise microscópica do órgão.

O diagnóstico de yersiniose tem sido baseado no cultivo do agente de fezes e/ou de tecidos afetados (Rabson et al. 1972, Greene 2006). 0 isolamento bacteriano do agente 
nesse caso foi observado no fígado, baço, intestino e pulmões dos animais acometidos, demonstrando ser uma infecção sistêmica. Yersinia spp. podem ser isolada de fezes de bovinos, ovinos, caprinos e cervídeos saudáveis (Fenwick \& Collet 2004), porém neste caso o isolamento do agente nas fezes das chinchilas foi obtido de animais provenientes de propriedades com surto de yersiniose além de serem animais com sinais clínicos da doença.

0 diagnóstico diferencial deve ser feito com outros agentes bacterianos como Francisella tularensis, Yersinia pestis, Y. pseudotuberculosis e Clostridium piliforme que são patógenos que causam lesões similares em roedores e lagomorfos (Wobeser et. al. 2009). Francisella tularensis causa granulomas com áreas centrais de necrose particularmente em rins e pulmões e ocasionalmente no fígado, baço, medula óssea e linfonodos (Mörner et al. 1988). A infecção em roedores por $Y$. pestis causa necrose coagulativa multifocal hepática muitas vezes com a formação de abscessos, pneumonite intersticial aguda difusa, atrofia linfoide do baço e esplenite com ou sem a formação de microabscessos (Coutinho et al. 1982). As lesões microscópicas por $Y$. pseudotuberculosis consiste em centros necróticos com bactérias circundados por macrófagos e lesões necróticas intestinais com inúmeros micro-organismos observadas da mucosa até a muscular. $Y$. pseudotuberculosis geralmente causa infecções sistêmicas mais comumente que $Y$. enterocolitica (Fenwick \& Collett 2004). Na doença de Tizzer (C. piliforme) observa-se infiltrado de neutrófilos e células mononucleares presentes nas margens das lesões necróticas com numerosos organismos visíveis pela hematoxilina e eosina podendo ser utilizadas colorações especiais como Warthin-Starry ou Prata de Gomori para evidenciar o bacilo (Greene \& Jones 2006).

Bottone et al. (1999) relataram que a infecção sistêmica por $Y$. enterocolitica ocorre tanto em hospedeiros normais bem como em imunodeprimidos. A infecção pela Yersinia enterocolitica nesse caso pode ter ocorrido devido à introdução de novos animais nos criatórios. Como o sistema de criação de chinchilas permite o acesso de um macho a várias fêmeas estes podem estar contribuindo para a disseminação do patógeno nos criatórios. Com isso pode se concluir que a Yersinia enterocolitica causa uma doença importante na criação de chinchilas e que deve ser considerada em casos de mortalidade nesta espécie.

Agradecimentos.- Aos demais membros do Setor de Patologia Veterinária da UFRGS pelo auxílio técnico. À Coordenação de Aperfeiçoamento de Pessoal de Nível Superior (CAPES) e ao Conselho Nacional de Desenvolvimento Científico e Tecnológico (CNPq) pelo auxílio financeiro deste trabalho.

\section{REFERÊNCIAS}

Autenrieth I.B. \& Firsching R. 1996. Penetration of M cells and destruction of Peyer`s patches by Yersinia enterocolitica: An ultrastructural and histological study. J. Med. Microbiol. 44:285-294.

Bottone E.J. 1999. Yersinia enterocolitica: overview and epidemiologic correlates. Microbes Infect. 1:323-333.

Coutinho E.M., Almeida A.M.P. \& Almeida C.R. 1982. Histopatologia da infecção por Yersinia pestis em roedores de focos de peste do Nordeste Brasileiro. Mem. Inst. Oswaldo Cruz 77(2): 139-151.

Donnelly T.M. 2004. Diasease problems of chinchillas, p.255-265. In: Quesenberry K.E. \& Carpenter J.W. (Eds), Ferrets, Rabbits and Rodents Clinical Medicine and Surgery. Saunders, St Louis.

Fenwick S.G. \& Collet M.G. 2004. Yersinia spp. infections, p.1617-1627. In: Ibid. (Eds), Infectious Disease of Livestock. Oxford Southern Africa, Cape Town.

Fukushima H., Saito K., Tsubokura M., Otsuki K. \& Kawaoka Y. 1983. Isolation of Yersinia spp. from bovine feces. J. Clin. Microbiol. 18:981-982.

Fukushima H., Nakamura R., Iitsuka S., Tsubokura M., Otsuki K. \& Kawaoka Y. 1984. Prospective systematic stydy of Yersinia spp. in dogs. J. Clin. Microbiol. 19:616-622.

Greene C.E. 2006. Yersiniosis, p.361-362. In: Ibid. (Ed.), Infectious Diseases of the Dog and Cat. $3^{\text {rd }}$ ed. Saunders Elsevier, St Louis.

Greene C.E \& Jones B.R. 2006. Tyzzer`s disease, p.362-363. In: Greene C.E. (Ed.), Infectious Diseases of the Dog and Cat. $3^{\text {rd }}$ ed. Saunders Elsevier, St Louis.

Mörner T., Sandström G., Mattsson R. \& Nilsson P. 1988. Infections with Francisella tularensis biovar palaearctica in hares (Lepus tumidus, Lepus europaeus) from Sweden. J. Wildl. Dis. 24(3):422-433.

NCCLS 2002. Performance Standards for Antimicrobial Susceptibility Testing. Twelfth Information Supplement 22(1). Wayne, Pennsylvania.

Oellerich M.F., Jacobi C.A., Freund S., Niedung K., Bach A., Heesemann J. \& Trülzsch K. 2007. Yersinia enterocolitica infection of mice reveals clonal invasion and abscess formation. Infect. Immun. 75:3802-3811.

Pai C.H., Mors V. \& Seemayer T.A. 1980. Experimental Yersinia enterocoliti$c a$ enteritis in rabbits. Infect. Immun. 28:238-244.

Prophet E.B., Mills B., Arrington J.B. \& Sobin L.H. 1992. Laboratory Methods in Histotechnology. Armed Forces Institute of Pathology, Washigton, DC. 279p.

Quinn P.J., Carter M.E., Markey B. \& Carter G.R. 1999. Section 2: Bacteriology. 18. Enterobacteriaceae, p.234-236. In: Ibid. (Ed.), Clinical Veterinary Microbiology. Elsevier, St Louis.

Rabson A.R., Koornhof H.J., Notman J. \& Maxwell W.G. 1972. Hepatosplenic abscesses due to Yersinia enterocolitica. Brit. Med. J. 4:341.

Raevuori M., Harvey S.M. \& Pickett M.J. 1979. Yersinia enterocolitica experimental pathogenicity for chinchilla. Acta Vet. Scand. 20:82-91.

Slee K.J. \& Skilbeck N.W. 1992. Epidemiology of Yersinia pseudotuberculosis and Y. enterocolitica infections in sheep in Australia. J. Clin. Microbiol, 30:712-715.

Vesselinova A., Najdenski H., Nikolova S. \& Wesselinova D. 2001. Arthritis after experimental infection with Yersinia enterocolitica 0:3 in rabbits. J. Vet. Med. B 48:43-53.

Wobeser G., Campbell G.D., Dallaire A. \& McBurney S. 2009. Tularemia, plague, yersiniose, and Tyzzer's disease in wild rodents and lagomorphs in Canada: A review. Can. Vet. J. 50:1251-1256. 